\title{
AN ANALYSIS OF INDONESIA ENGLISH CODE MIXING IN FACEBOOK STATUS USERS
}

\author{
Windyawati $^{1}$, Yulianti Octavia Aurima ${ }^{2}$ \\ ${ }^{1}$ IKIP Siliwangi \\ ${ }^{2}$ IKIP Siliwangi \\ ${ }^{1}$ windy.windyawati@yahoo.com, ${ }^{2}$ yuliaurima@gmail.com
}

\begin{abstract}
This research investigates the use of code mixing in Facebook by Indonesian people. The purpose of this study is to describe the kind of code mixing used by Indonesian people in Facebook status users. This research employs the descriptive qualitative method. The data were taken from the Indonesian Facebook users posting. The data are analyzed based on Suwito's theory. The results show that there are six types of linguistic forms of code mixing consisting of 11 data or $22 \%$ form of word; 21 data or $42 \%$ data phrase; 2 data or $4 \%$ repetition; 6 data or 12\% idiom; 9 data or $18 \%$ clause; 1 data or $2 \%$ hybrid. Thus, the conclusion of this research is the students use two languages i.e. Indonesia and English as code mixing, and the researchers found the Facebook status users used code mixing of the phrase in the most form of code mixing.
\end{abstract}

Keywords: Sociolinguistic, Code Mixing, Facebook

\section{INTRODUCTION}

Code-mixing are part of the study of bilingualism in sociolinguistics which have become a very popular language, this becomes an influence for smooth communication in Indonesia as it is widely used by people in its Facebook status who are aware of code-mixing using other languages like Indonesian and English. In a social media where people talk in excess of one dialect, there is normally a dialect that is normally impacted by the others. A portion of the impacts of multilingualism are code-blending and code-exchanging, bilingualism, diglossia, and so on. At the point when a speaker interacts with at least two dialects they may start to utilize the dialects together despite the fact that it won't not be with rise to capability.

However, these languages affect the other and frequently prompt code-blending. Code combining is two dialects utilized by the acquainted to the degree that they change from one dialect into another over the span of single expression (Wardhaugh, 1986). Web-based social networking is the group of online correspondences channels to gave network based information, association, content-sharing and joint effort. The varieties of social media, such as twitter, Facebook, YouTube, Flickr, podcasting, and so on. According to (Cook \& Hopkins, 2008), "social media is a tool that allow for far greater levels of two - way interaction, discussion, and conversation".

Media communication is very primary to people's lives. In simple terms, a communication medium is an intermediary in conveying an information from the communicator to the communicant which aims to be efficient in disseminating information or message. Communication is a form of conversation that takes place on the basis of perception. Much of the world's communications are done in English. 80\% of the world's electronically stored information is in English. Communication divided into two category, they are direct 
communication and indirect communication. The various of indirect communication is line, twitter, facebook, path and instagram.

Facebook is the biggest long range interpersonal communication site on the planet, clients can share photographs and video, and taskting to each other. As indicated by measurements from the Nielsen Gathering, Web clients inside the Unified States invest more energy in Facebook than some other site. On Facebook, most people write informally. The language that used by people to write status on Facebook usually is informal language. This language many poor spelling and decline in Standard English. The idea that virtual sociability, at least as an ideal, is a late-modern from of social aggregation that is profoundly ambiguous. People may use more than one language when they write status on Facebook"

This research is An Analysis of Indonesian English Code Mixing in Facebook Status Users. The data of this research come from the statuses which are posted by Indonesian Facebook users and the correspondences. They were one thirty Indonesian Facebook users which are friend with the researchers. The researchers interested to this topic because it is as a recent phenomenon in the social media networking especially Facebook.

\section{Sociolinguistic}

Sociolinguistic is a investigation of the connection amongst dialect and society. They are keen on clarifying why we talk distinctively in various social settings, and they are worried about distinguishing the social elements of dialect and the ways it is utilized to pass on social significance.According to (Holmest, 2001) Looking at the way individuals utilize dialect in various social settings gives an abundance of data about the way dialect works, and additionally about the social connections in a network, and the way individuals flag parts of their social character through their dialect.

Then, plainly sociolinguistics contemplates in multilingual networks should include "codeswitching", "code-mixing", and the use of "mixed codes". The purpose of these statement that with sociolinguistic learning communication which work ship with the language where it is contained in code, case of the code, and event use of code-mix. In this case language will be found to vary according to diversity in a society, thus social diversity influences the variety of a language.

\section{Bilingualism}

When two or more language used alternately by the same speaker, it can be said that those languages contact each other. Events using multilingual language alternately by a speaker called bilingualism. Someone who wants to use two languages, of course, they must master the two languages. They must master mother tongue and another language that become a second language. When the people use two languages to interact with other people they become bilingual that means they realize bilingualism.

(Bialystok, 2006) describes a bilingual individuals as the one who speaks equally two languages, who also acts appropriately in a sociocultural way in both languages. On the other hand, (Titone, 1993) suggests that bilingualism is in the ability to speak a second language using structures and concepts distinctive to that language, instead of paraphrasing from the 


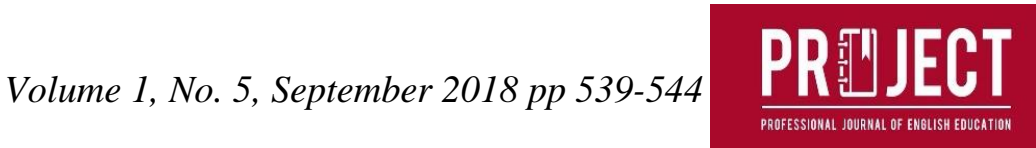

native language. These examples show that defining bilingualism is problematic since individuals with varying bilingual characteristics may be classified as bilingual.

In Indonesian bilingualism is called kedwibahasaan (Chaer \& Agustina, 1995). Of the terms argue by Chaer, in daily activities, bilingualis is relating to being kedwibahasaan in use by those speakers are bilingual. According to (Sumarsih, Masitowarni, Bahri, \& Sanjaya, 2014) stated that "the practice of bilingualism is alternately from one to another language by a speaker". Then, Bloomfield (Sumarsih et al., 2014) also found that "bilingualism is the skill of a speaker to use two languages equally well". Thus, it means that bilingualism is the use of two languages by a speaker in the interaction with the speaker of another language. Most of Indonesian people have ability either to speak and understand two languages or even more. There are some factors why a person can be a bilingual. Such as mobilization, nationalism, education, culture, or religion.

\section{Code Mixing}

Language code to other language code, such as code A (Indonesian Language) who switch to code B (English Language) the transitional use of such language is called code-switching. So, code-switching is changing one language code to another language code in a conversation, while the code mixing is mixing two one of the effects of using two or more languages or bilingualism is code mixing. A code is a language, a variety of language. A code is a classspecific language variation, especially for the different strategies of verbal planning. Codeswitching and code-mixing are a division of code. Code-switching is the transition from one languages or more in a conversation, but it does not change the overall language of the other languages.

Code-Mixing is a term used in bilingualism area. According to (Bhatia \& Ritchie, 2004) Codemixing refers to "linguistic behavior of a bilingual speaker who insert the words or phrases from one of his languages into the other one". Considering that code-mixing enable to change of code, it is important to know factors that can cause code mixing. The phenomenon of code mixing happens not only between local language and Indonesian language but also among local language, Indonesian language, and English.

Code mixing usage depends on what language that the aim of the speakers is. For instance, code mixing used in social networking facebook. Code mixing in facebook is found when speaker mixes two languages to achieve a particular purpose. Other definition from Suwito; that idea of code blending is the utilization two laguages or more by embeddings the components of one dialect to the next, which is utilized consistenly. Besides, Suwito states if in an expression there is a blending mix between assortments of dialects in a same condition, it is called code blending. What he means by the language varieties here are dialect, registers, styles, etc.

Code mixing is usually occurs amidst a sentence. According to (Suwito, 1985) based on the unsure of language that involve in it, there are some forms of code mixing, they are:
a) Word insertion
c) Idiom or expression insertion
b) Phrase insertion
d) Hybrid insertion
c) Reduplication insertion.

\section{Facebook}

Informal communities are self-sorting out, rising, and perplexing, with the end goal that a universally rational example shows up from the neighborhood association of the components that make up the framework. These examples turn out to be more evident as system estimate increments. There are some examples of social networks: bebo, classmates, Facebook, Line, 
Instagram, BBM, friendster, Google+, Path, StumbleUpon, Yik Yak, Twitte, and YouTube . Facebook is a company and online person to person communication benefit headquartered in Menlo Stop, California, in the Assembled States. Its site was impelled on February 4, 2004, with Check Zuckerberg with his Harvard School level mates and related understudies Eduardo Saverin, Andrew McCollum, Dustin Moskovitz and Chris Hughes.

Facebook is a long range interpersonal correspondence site and organization where customers can post comments, share photographs and associations to news or other intriguing substance on the web, play amusements, talk live, and stream live video. According to (Jefferi A, 2011) states that Facebook is a global long range interpersonal communication site that boasts 350 million registered users. Facebook user can add friends to their facebook network to whom they send message, profile updates, pictures, and the like. Facebook is a social networking site that is currently booming in cyberspace (Nilawati, 2010).

\section{METHOD}

In doing this research the researchers focused on finding the code mixing by Indonesian people as Facebook user which are friend with the researcher, the type of this research is descriptive qualitative because the researchers describes the linguistic form of code mixing. Subjective research is most appropriate to address an exploration issue in which you don't have a clue about the factors and need to investigate. The writing may yield little data about the marvel of study, and you have to gain more from members through investigation (Creswel, 2012).

The participants of the research are entire of writers Facebook account friends. Meanwhile, the participants of the research are forty-four users. The subject of this research is the IndonesianEnglish code mixing sentences which are found in Indonesian people post. The researchers applies documentation as the way to collect the data. The researchers open a Facebook account (online) and the researchers observed activities Facebook friends, by reading status. When it finds a sentence that includes code mixing, the researchers take as an example.

The collected data were identified, classified, analyzed based on code mixing. The researchers analyzed the data accordance with the theory analysis of (Suwito, 1985). The code mixing in the form of words, phrase, repetition word, idioms, and clause." To find out the presented categories of code mixing used in their Facebook status. The percentage is determined by using the formula (Creswell, 2003);

$$
\begin{aligned}
& \text { Formula: } P=\frac{F}{N} \times 100 \% \\
& \text { Explanation: } \\
& \mathrm{P}=\text { as percentage } \\
& \mathrm{F}=\text { as frequency of code mixing } \\
& \mathrm{N}=\text { as total code mixing }
\end{aligned}
$$

\section{RESULTS AND DISCUSSION}

\section{Results}

The researcher found a classification of code mixing used by the Facebook status users. They are word, phrase, repetition, idiom, clause, and hybrid. The analysis of research finding from the participant, the researchers found the Facebook status users used code mixing of the "phrase" in the most form of code mixing because this is the easiest form.

a. Word insertion 
For the example data: "saatnya jadi auntie teladan yang menjaga keponakannya dengan penuh kasih saying". Morphologically the underlined word is a single word, because it is small's meaningful linguistic unit that can be used on its own. Auntie is a base or an origin word syntactically it is included as a noun used in the sentence.

b. Phrase insertion

For the example data: "jangan langsung negative thinking". Negative thinking is a noun phrase which consists of two words, stand as a modifier and by a headword.

c. Repetition insertion

For the example data: "setelah UAS waktunya happy happy bersama teman". The word happy happy is a form of word repetition, because the word happy is written twice in the sentence completely. Actually English has no reduplication. The sense of repetition is coming from Indonesian language. So the word happy happy is using Indonesian system and concept but it's written in English.

d. Idiom insertion

For the example data: "terimakasih selalu stand by buatku kapanpunaku butihkan" stand $\underline{b y}$ is idiom, and the sentence of stand by is new meaning of each word.

e. Clause insertion

For the example data: "jadi mending lupain aja/ they don't worth it". They don't worth it is an independent clause, because there is a subject and predicate in the sentence. In this clause, the subject is they, the predicate is $\underline{\text { don't. }}$.

f. Hybrid insertion

For the example data: "bahagia itu simple, sesimple saat seseorang memuji matamu dan kau tersenyum karenanya... let your eyes talk”. The word sesimple is a hybrid, because the word simple is English word and the word se is Indonesian prefix.

\section{Discussion}

The subject of the research is an Indonesian people in social media networking (Facebook) users who are friends with researchers, the object of research is the use of code-mixing by Indonesian people in social media networking (Facebook). The instrumentation of this research is documentation, the documentation is saving and documenting the timeline which is taken from the observation.

In this research, the researchers found 50 data of Indonesian-English code mixing in Facebook which consists of 11 data or $22 \%$ form of word, 21 data or $42 \%$ data phrase. 2 data or $4 \%$ repetition, 6 data or $12 \%$ idiom, 9 data or $18 \%$ clause, 1 data or $2 \%$ hybrid. Analysis of research finding code mixing used by Facebook status users are written.

\section{CONCLUSION}

Based on data analysis, researchers conclude that code-mixing is the use of two or more languages by transferring from one language to another; for example from Indonesian to English from English to Indonesian in user from Facebook without changing the meaning of the sentence. In this research the Facebook users which are friends with the researcher employ code mixing by inserting the linguistic elements of English into Indonesian in their statuses. The researchers found that the correspondences used code mixing when they were posting a status on their Facebook account.

Furthermore, the elements that are uttered in their conversation are called outer code mixing because of those elements from a foreign language. Researchers found the use of code mixing 
in the form of words, phrases, hybrids, idioms, and repetitions. This research data is taken from the timeline, and the researchers found 50 statements on the Facebook social network that is using code mixing consisting of 11 data or $22 \%$ form of word; 21 data or $42 \%$ of data phrases; 2 data or $4 \%$ repetitions; 6 data or $12 \%$ idioms; 9 data or $18 \%$ clauses; 1 data or $2 \%$ hybrids.

\section{ACKNOWLEDGMENTS}

We sincerely appreciate the parties who had directly and indirectly support this paper in any aspects until it is completed, especially to Mrs.Yanuarti as the supervisor, who has helped the authors with the prior revision, and to the whole reviewers of PROJECT who has helped publishing this work.

\section{REFERENCES}

Bhatia, T. K., \& Ritchie, W. C. (2004). The Handbook of Bilingualism. Blackwell Pub. Retrieved from https://books.google.co.id/books?hl=id\&lr=\&id=tB3zbSCYzUC\&oi=fnd\&pg=PA114\&dq=Bilingualism + and+second+language+acquisition.+ in:bra thia,+tej+k.\%3B+ritchie,+william+c.+the+handbook+of+bilingualism.+malden:+blackw ell.+\&ots=4ekdhPPIyT\&sig=ouqThlQogWeUyXprIq5-

Bialystok, E. (2006). Bilingualism in development: language, literacy \& cognition. UK: Cambridge University Press.

Chaer, A., \& Agustina, L. (1995). Sosiolinguistik Perkenalan Awal. Jakarta: Rineka Cipta.

Cook, \& Hopkins. (2008). Social Media. Australia: Your Organisation \& web2.0.

Creswel, J. W. (2012). Educational Research: Planning, Conducting, and Evaluating Quantitative and Qualitative Research. Retrieved from http://www.scis.nova.edu/ nasutif/MCTE690-syllabus-summer2003.pdf

Creswell, J. W. (2003). Research Design: Qualitative and Quantitative Approaches. US: Sage Publications, Inc. Retrieved from http://psycnet.apa.org/record/1996-97121-000

Holmest, J. (2001). An Introduction to Contact Linguistics (2nd ed). Retrieved from https://rovcv5kkd07.storage.googleapis.com/MDYzMTIxMjUxNQ==07.pdf

Jefferi A, R. (2011). Social Media Derictory. United States of America: Pearson Education, Inc.

Nilawati. (2010). Functions and Reasons for Code-Switching On Facebook By Utar EnglishMandarin Chinese Bilingual Undergraduates. Retrieved from http://eprints.utar.edu.my/263/1/EL-2011-0803813-1.pdf

Sumarsih, S., Masitowarni, S., Bahri, S., \& Sanjaya, D. (2014). Code Switching and Code Mixing in Indonesia: Study in Sociolinguistics? English Language and Literature Studies, 4(1), 77. https://doi.org/10.5539/ells.v4n1p77

Suwito. (1985). Alih Kode, Campur Kode, Interferensi. Surakarta: Binary Offset.

Titone. (1993). Bilinguismo precoce ed educazione bilingue. Roma: Armando Editore.

Wardhaugh, R. (1986). an Introduction to Sociolinguistics. Great Britain: Hrtnolls Ltd, Bodmin. 